\title{
TRADICIÓN Y NOVEDAD DEL EXEMPLUM LULIANO: EL ARBRE EXEMPLIFICAL*
}

\author{
José Aragüés Aldaz \\ Universidad de Zaragoza \\ jaragues@unizar.es
}

Diseñado en plena fase ternaria del Arte, el Arbre de ciència de Ramon Llull (1295-1296) concilia varios propósitos. Sus catorce primeros libros ofrecen un completo recorrido por todos los ámbitos del conocimiento (en lo que constituye también un cuidado itinerario por la escala del ser), al tiempo que pretenden hacer algo más accesibles los principios lógico-demostrativos expuestos por el autor en su reciente Tabula generalis (1293-1294). Los dos últimos libros del Arbre de ciéncia, por su parte, se destinan a repasar los contenidos previos de la obra, deduciendo de los mismos dos ordenadas series de «ejemplos»y «cuestiones». Esos dos apéndices, presentados bajo los títulos de Arbre exemplifical y Arbre qüestional, clausuran así el programa didáctico luliano, pero también lo reiteran, arrojando sobre él una nueva luz ${ }^{1}$.

De acuerdo con esa misión tan específica, no resulta casual que los acercamientos críticos al Arbre exemplifical se hayan encaminado, esencialmente, al desentrañamiento del sentido alegórico de algunas de sus secuencias: es decir, a la dilucidación de la relación exacta entre las mismas y la teoría artística que aspiran a iluminar. Al asunto (capital no sólo para el conocimiento de la cuentística del Beato sino también para la comprensión de la misma estructura del Arte) se han consagrado algunas páginas ciertamente brillantes.

\footnotetext{
* El presente trabajo se ha beneficiado del apoyo del Proyecto de Investigación FFI2013-43927-P («La literatura hagiográfica catalana, entre el manuscrito y la imprenta») y se integra en el marco de las investigaciones del Grupo Clarisel, financiado por el Gobierno de Aragón y el Fondo Social Europeo.

${ }^{1}$ Arbre de ciència, ed. de Joaquim Carreras i Artau y Tomàs Carreras i Artau, en Ramon Llull, Obres essencials, ed. de Joaquim Carreras i Artau et alii, Barcelona, Selecta, 1957-1960, Vol. I [1957], pp. 5551046. Me sirvo así mismo de la excelente versión al castellano incluida en Ramon Llull. Obra escogida, ed. de Pere Gimferrer y Miquel Batllori, Madrid, Alfaguara, 1981, pp. 517-617.
} 
Piénsese en el trabajo de Robert Pring-Mill sobre la secuencia que abre la serie, pionero a tantos propósitos, o en la lúcida exégesis de un ramillete de ejemplos especialmente complejos emprendida por Lluís Cabré, Marcel Ortin y Josep Pujol. Y piénsese también en la esclarecedora mirada de Lola Badia a tres de los cuentos de mayor relevancia literaria de la obra, o en el jugoso análisis, debido a Albert Hauf, de una retahíla de narraciones encadenadas allí por el Beato, inmerso en un más ambicioso estudio de las claves estéticas y filosóficas del conjunto².

Las páginas que siguen tienen, por fuerza, una intención más modesta. De hecho, tan sólo pretenden recorrer algunas de las formas que se dan cita en el Arbre exemplifical, para indagar aquella tensión entre la tradición y la novedad que parece condicionar su formulación en el texto. Es asunto senci1lo, pero quizá también útil a la hora de entender la «diacronía» interna de la literatura ejemplar luliana: es decir, la conformación, por parte del autor, de un corpus cuentístico en última instancia proteico, hábilmente adaptado a los sucesivos contextos discursivos y literarios que le sirven de marco.

\section{Diacronías}

El Arbre exemplifical ofrece numerosos motivos de reflexión al propósito de esa evolución de la escritura del Beato. Por supuesto, la presencia de formas breves de carácter comparativo puede rastrearse ya en el pre-artístico Llibre de contemplació (¿1273-1274?) y en diversos tratados pedagógicos de la etapa cuaternaria (1274-1290), como el Llibre de l'Orde de cavalleria, la Doctrina pueril o el algo más tardío Llibre d'intenció. Por esas mismas fechas, incluso, los Començaments de medicina habían de otorgar carta de naturaleza a una nueva especie (la matafora luliana), creada por el autor para

\footnotetext{
${ }^{2}$ Robert D. F. Pring-Mill, «Els recontaments de l'Arbre Exemplifical de Ramon Llull: la transmutació de la ciència en literatura» [1976], en Estudis sobre Ramon Llull (1956-1978), Barcelona, Curial Edicions-Publicacions de l'Abadia de Montserrat, 1991, pp. 307-317; Lluís Cabré, Marcel Ortin y Josep Pujol, «"Coneixer e haver moralitats bones". L'ús de la literatura en l'Arbre exemplifical de Ramon Llull», en Estudios Lulianos, 28 (1988), pp. 139-167; Badia, Lola, «La literatura alternativa de Ramon Llull: tres mostres», en Actes del VII Congrés de l'Associació Hispànica de Literatura Medieval (Castelló de la Plana, 22-26 de setembre de 1997), ed. de S. Fortuño Llorens y T. Martínez Romero, Castellón de la Plana, Publicacions de la Universitat Jaume I, 1999, vol. I, pp. 11-32; Albert G. Hauf, «Sobre l'Arbor exemplificalis», en Arbor Scientiae. Der Baum des Wissens von Ramon Llull, ed. de F. Domínguez Reboiras, P. Villalba Varneda y P. Walter, Brepols, Turnhout, 2002, pp. 303-342. Al propósito específico de uno de esos ejemplos, añádase Lola Badia y Anthony Bonner, Ramón Llull: Vida, pensamiento y obra literaria, Barcelona, Sirmio, 1993, pp. 152-155. Un excelente panorama en torno al texto, en Lola Badia, Joan Santanach y Albert Soler, «Ramon Llull», en Historia de la Literatura Catalana, dir. de À. Broch, vol. I (Literatura medieval (I). Dels origens al segle XIV, dir. de L. Badia), Barcelona, Enciclopèdia Catalana-Barcino-Ajuntament de Barcelona, 2013, pp. 377-476, esp. pp. 459-464.
} 
trasladar los presupuestos analógicos del ejemplarismo elemental, mecanismo esencial de demostración en esa primera etapa del Arte. Con todo, había de ser en el seno de la novela donde las formas breves de carácter narrativo (la fábula, el cuento verosímil y el relato de tema mariano) hallaran su ámbito de expresión más fecundo, asumiendo un espacio cada vez más amplio. Basta una simple mirada al Blaquerna (1276-1283) y al Llibre de meravelles (1287-1289) para comprenderlo. Si la primera era una novela decorada ocasionalmente con ejemplos, el Llibre de meravelles testimonia ya la inversión de ese esquema, al punto de convertir su delgada trama dialógica en un útil marco para la inserción de un caudal cuentístico enorme. El paso de la fase cuaternaria a la etapa ternaria (1290-1308), por su parte, impuso a la literatura ejemplar luliana algunos obstáculos teóricos, cuyas consecuencias no resulta sencillo evaluar. El cambio del paradigma que sustentaba el Arte (es decir, la sustitución del ejemplarismo elemental por un modelo explicativo de la realidad de carácter intrínseco, basado en la teoría de los correlativos) pudo provocar un cierto declive en el uso de la recién mencionada matafora, al menos tal y como ésta había sido concebida en los Començaments de medicina. Pero la utilidad de esa especie será todavía ponderada en el texto fundador de la etapa ternaria (el Ars inventiva veritatis) y, en cualquier caso, el mencionado cambio de paradigma no parece haber afectado sustancialmente al resto de las variedades del ejemplo empleadas por Llull. Como tampoco parece haberlo hecho el abandono simultáneo de los tanteos del autor en el ámbito de la novela. Por el contrario, acaso la consecuencia más clara de ese abandono fuera la focalización de su vocación literaria en el género ejemplar. Olvidada o abandonada la intención de «novelizar» su teoría, el Beato depositó en cuentos y símiles esa misión de «transmutación de la ciencia en literatura» imprescindible para la difusión del Arte. Y lo hizo con una convicción absoluta, según demuestra la sola escritura del Arbre exemplifical, «lugar privilegiado -al decir de Badia- de esa nueva literatura luliana donde el saber y su expresión placentera convergen ${ }^{3} \gg$.

\footnotetext{
${ }^{3}$ Véase, ante todo, L. Badia, art. cit., p. 12. Y, por supuesto, R. Pring-Mill, art. cit., al propósito de esa «transmutación de la ciencia en literatura». Para las consecuencias del cambio de paradigma artístico en el uso de los procedimientos metafóricos, véanse L. Badia y A. Bonner, ob. cit., p. 92. Para la matafora, Eugènia Gisbert, «Metaforice loquendo: de l'analogia a la metàfora en els Començaments de medicina de Ramon Llull», en Studia Lulliana, 44 (2004), pp. 17-52. Y añádase, al propósito general de la diacronía de la literatura ejemplar luliana, José Aragüés, «Llull and Medieval Exemplary Literature», en A Companion to Ramon Llull, ed. de M. D. Johnston y A. M. Austin, A Companion to Ramon Llull, Leiden, Brill, en prensa.
} 
A esa luz, la literatura ejemplar logró consolidar en el Arbre exemplifical aquel lugar preferencial que, de manera paulatina, había ido ganando en los textos anteriores del autor. Aunque hubo de hacerlo a cambio de algunos tributos y de no pocas transformaciones. Nacidos al amparo teórico del riguroso Arbre de ciència, los ejemplos del tratado mostrarán una servidumbre inflexible hacia los principios artísticos, asumiendo al tiempo las novedades impuestas por su formulación ternaria (aunque todavía se perciban en ellos diversos ecos del ejemplarismo elemental propio de la fase anterior). De modo inevitable, la trama narrativa de muchas de esas secuencias cobrará así un nuevo aspecto, mucho más osado y original. Sus protagonistas serán personificaciones correspondientes a los más diversos objetos y entes naturales (el escudo, la espada, la rosa, la pimienta, un herpes), y a cualquiera de las realidades abstractas que asoman por las páginas teóricas del Arte (de las figuras geométricas a las dignidades divinas o las potencias del alma). Estos extraños cuentos (llamémosles «artísticos») afloran por primera vez en el Arbre exemplifical. La elección de esa modalidad narrativa parece, así pues, dictada únicamente por las necesidades específicas de su propio marco discursivo. Y, aunque quizá transparente un cierto deseo de explorar nuevos horizontes para el género, no implicó una quiebra en la confianza del autor hacia el resto de las formas ensayadas con anterioridad. La fábula y el cuento verosímil seguirán teniendo, como veremos, una cierta presencia en el tratado. Y, de hecho, ambas especies convivirán todavía con esos novedosos relatos «artísticos» en la sección de pulcra exempla de la tardía Rhetorica nova (1301), erigida en una suerte de registro de todas las categorías ejemplares contempladas en algún momento por el Beato.

No faltan otros indicios de ese giro impuesto por el Arbre exemplifical a la trayectoria de la literatura ejemplar. Por primera y por última vez, seguramente, esa literatura aparece allí escindida en dos categorías posibles -la de los «relatos» y la de los «proverbios»- marcando el inicio del interés del autor por este segundo género, de gran relevancia en su producción posterior. Con todo, quizá las novedades más significativas sean las que afectan a la propia arquitectura de la obra. En el Arbre exemplifical, las secuencias simplemente se yuxtaponen, ajenas a cualquier marco novelístico y alejadas de aquellos contenidos (los de los libros previos del Arbre de ciència) que iluminan. Concebido como una colección exclusiva de formas breves, el texto desborda además su condición de mero apéndice de aquella enciclopedia, para adquirir todo el aire de un instrumentum, de un útil repertorio de formas aptas para ser reutilizadas por el lector en su propio discurso. Ello no implica, claro está, que su diseño final carezca de interés: la ordenada sucesión 
de los ejemplos del Arbre exemplifical impone un cuidado recorrido por la arquitectura analógica del universo, una relectura sistemática del Libro de la Creación. Y no faltan en el interior de los relatos algunos casos curiosos de coordinación y subordinación narrativas, al modo de los propuestos en el Llibre de meravelles.

Por lo demás, aquel aire «experimental» que ostentaban en ocasiones los cuentos lulianos había de cobrar en la obra un tono mucho más acusado. La sola presencia de los mencionados relatos «artísticos» nos sitúa, en efecto, en una atmósfera de absoluta irrealidad, mostrando toda la voluntad de manipulación y transgresión de las fronteras del género que guía al autor. Rotas todas las convenciones de la cuentística tradicional, el ejemplo «artístico» adopta en algunas ocasiones el aspecto de un mero constructo o artificio verbal. De modo indisimulado, la generación de muchas de esas secuencias obedece además a un proceso combinatorio casi mecánico, resuelto en la ordenada fabricación de tramas narrativas a partir de una recreación sistemática de las relaciones entre los entes expuestas en el Arbre de ciència. Esas secuencias, además, son presentadas como modelos o arquetipos, susceptibles de ser imitados o readaptados de acuerdo con las conveniencias del propio discurso. El texto convoca así al lector a una tarea de ejercitación narrativa y «artística» que se quiere universal. Ese es, obviamente, el mayor signo del lugar que las formas breves habían adquirido en la obra del Beato a la altura de $1295^{4}$.

\section{Las misiones del texto}

El modelo remoto del Arbre de ciència puede rastrearse en las pequeñas enciclopedias para uso de laicos difundidas en la época. Su diseño, sin embargo, es específicamente luliano. El texto ofrece, como decíamos, un análisis sistemático de todas las esferas de la realidad a través de sus primeros catorce libros o árboles (elemental, vegetal, sensual, imaginal, humanal, moral, imperial, apostolical, celestial, angelical, eviternal, maternal, cristianal y divinal), cada uno de ellos distribuido en siete secciones: raíces, tronco, ramas, ramos, hojas, flores y frutos ${ }^{5}$. Engarzado como penúltimo libro de la obra, el Arbre exemplifical alberga también sus correspondientes siete secciones, de las raíces a las flores. Y todas ellas son susceptibles de dividirse a su vez en

\footnotetext{
${ }^{4} \mathrm{Al}$ respecto de ese carácter experimental, me permito remitir de nuevo a J. Aragüés, art. cit., y «Cuentos efímeros. Ejemplo verosímil y diálogo en el Llibre de meravelles», en Caplletra, en prensa.

${ }^{5}$ Para la concepción del texto como enciclopedia, véase Lola Badia, «The Arbor scientiae: A 'new' encyclopedia in the thirteenth-century Occitan-Catalan cultural context», en Arbor Scientiae. Der Baum des Wissens von Ramon Llull, cit., pp. 1-19. Para la relación de su estructura con el Arte, L. Badia, J. Santanach y A. Soler, art. cit., esp. pp. 459-461.
} 
catorce apartados, destinados a recoger los «ejemplos» relacionados con cada uno de los libros previos del conjunto. El diseño del opúsculo (como el del gemelo Arbre qüestional, que cierra la enciclopedia) acaba sugiriendo así la idea de una copia en miniatura del Arbre de ciència (aunque invertida, claro está, dada la subordinación aquí de los árboles a sus partes o secciones). Su sola contemplación delata no sólo el mencionado carácter reiterativo del proyecto didáctico del autor, sino también la concepción especular, concéntrica, de los textos que lo sustentan.

En cualquier caso, el del Arbre exemplifical es un diseño ideal, teórico, toda vez que el texto no desarrolla todos los apartados nacidos de esa doble división en secciones y árboles, como tampoco agota, por supuesto, todas las posibilidades temáticas que ofrecen los apartados en verdad considerados. Las ocupaciones del autor y la voluntad de brevedad hicieron que el Arbre exemplifical incluyera tan sólo una muestra de la materia que una completa «ejemplificación del Arte» podría aportar, según advertía explícitamente su prólogo. Una muestra válida, en cualquier caso, para que el lector pudiera «encontrar nuevos proverbios y nuevos relatos, y extender su entendimiento por la gran materia del Árbol ${ }^{6} »$. Desde esa perspectiva, el carácter incompleto del Arbre exemplifical se revela no tanto como una carencia, sino como una invitación a la participación del lector en la reflexión y en la propia divulgación metafórica del Arte, concebida esta última como una tarea, según decíamos, abierta e inacabada.

En ese mismo prólogo se anunciaba toda una galería de destinos posibles para la materia ejemplar y, de modo más específico, para la obra que el lector tenía en sus manos. Esa obra proporcionaba a este último una «doctrina para conocer los secretos naturales y sobrenaturales» (es decir para la comprensión de los saberes científicos recién expuestos en el Arbre de ciència), al tiempo que le iniciaba en la práctica intelectual de la meditación alegórica, proporcionándole un «hábito para entender muchas cosas placenteras de entender y placenteras de oír». Además, las secuencias aportaban algunas «moralidades buenas» y un «solaz» que, en buena medida, deberíamos identificar con el placer derivado del propio desentrañamiento de su significado metafórico. El reconocimiento luliano de esas cualidades asumía (pero sin duda también desbordaba) la triple utilidad del género para la ilustración, la persuasión moral y el adorno apreciada al unísono por la tradición retórica. Y en esas mismas cualidades residía, en definitiva, la utilidad «pública» de un repertorio cuyos contenidos podía proyectar el lector, según anunciaba

${ }^{6} \mathrm{XV}$, pról., p. 799. 
también aquel prólogo, hacia el ámbito de la predicación o el de la conversación amistosa.

Por supuesto, la lectura de las secuencias que integran el Arbre exemplifical muestra un notable predominio de la primera de las tres funciones mencionadas (la heurística o ilustrativa). Pero la intención ética o moral posee también allí un peso considerable. Esta última resulta especialmente evidente en los ejemplos referidos al Arbre moral (el sexto de los que componían el Arbre de ciència), pero impregna también otras muchas secuencias, sumándose (o subordinándose) a la mencionada voluntad heurística. La propia multiplicación de los niveles narrativos del texto (gracias al conocido procedimiento de las «cajas chinas») había de favorecer esa convivencia de enseñanzas complementarias.

Para comprobarlo, basta con observar el primero de los capítulos del texto, consagrado a las «Raíces del Arbre exemplifical». Esas «raíces» se identifican (como sucede en el resto de los libros del Arbre de ciència) con los dieciocho principios del Arte: de la Bondad a la Minoridad. El capítulo ofrece así un recorrido por esos principios a través de dieciocho secuencias referidas a la esfera de los cuatro elementos. Las secuencias proponen diversos encuentros y diálogos entre el agua, al aire, la tierra y el fuego, pero, a su vez, esos cuatro personajes introducen algunos cuentos intercalados. Estos últimos están destinados a ilustrar, por un procedimiento analógico y especular, las mismas tensiones existentes entre los elementos, aunque están ya protagonizados por diversos personajes alegóricos (como la Avaricia, la Sabiduría o la Voluntad) o por los personajes habituales del cuento verosímil luliano (reyes, nobles o labradores). Y es la aparición de unos y otros personajes la que, en efecto, posibilita la introducción de una trama de contenido moral en la obra, que se funde con la citada enseñanza heurística ${ }^{7}$.

El procedimiento es evidente en muchas otras secciones del Arbre exemplifical. La sección dedicada a los «ramos» incluye un ejemplo relativo a los contenidos del Arbre imaginal. Allí, la Vista y el Gusto intercambian dos relatos relacionados con el mal uso de la imaginación por parte de dos personajes: el hijo de un mercader, que gastó todo su dinero en la construcción de suntuosos palacios, y un príncipe avaricioso, que «imaginaba siempre» tesoros y acabó obligado a beber oro fundido ${ }^{8}$. Aquí Ramon Llull no parece considerar el ejemplo como un mero instrumento para la ilustración del Arte: por el contrario, contempla también ese Arte como el medio para la obtención

\footnotetext{
${ }^{7}$ Léase a esta luz, por ejemplo, el cuento protagonizado por la Voluntad y la Sabiduría, narrado por el Fuego: XV, I.4, p. 800.

${ }^{8}$ XV, IV.4, p. 819.
} 
de una materia ejemplar rica y variada, encaminada a la exhortación moral, de acuerdo con una visión del género algo más afín a la que presidía su uso en la oratoria y la literatura de la época.

\section{Proverbios ejemplares}

Muchas de las secuencias que integran el Arbre exemplifical (unas cuatrocientas cincuenta) constituyen, en puridad, proverbios. Como decíamos, se trata de la primera gran aportación luliana a ese género (aunque un relativo interés por las formas de carácter sentencioso o aforístico pueda rastrearse ya desde 1290, coincidiendo con la renovación de las técnicas demostrativas del Arte). En 1296, año en que concluye la redacción del Arbre de ciència, Ramon Llull dará a la luz el primero de sus repertorios exclusivos de proverbios (los Proverbis de Ramon), al que seguirán los proverbios de la Rhetorica nova y los Mil proverbis, todavía en la fase ternaria, y los Proverbis d'ensenyament, en los inicios de la etapa postartística'. La nutrida presencia del género en el Arbre exemplifical ha de entenderse así como el fruto de un auténtico hallazgo literario por parte del autor. Un hallazgo anunciado desde el citado prólogo del tratado, donde se declaraba la intención de «dividir en dos partes» los ejemplos propuestos: «a saber, en relatos (recontaments) y proverbios ( proverbis $\left.^{10}\right) \gg$.

Esa consideración del proverbio como «parte» (o quizá «especie») del ejemplo es tan ambigua como, en el fondo, desconcertante. Es obvio que la tradición retórica estableció una frontera entre ambos géneros. De hecho, la conciencia de esa frontera subyace en la proposición independiente de ambos tipos de secuencias en sendos capítulos de la tardía Rhetorica nova luliana. Y esa misma conciencia asoma por el propio interior del Arbre exemplifical: en el opúsculo, las series de proverbios son encabezadas siempre por este último término; a cambio, los relatos no se presentan bajo el rótulo de recontaments, sino directamente bajo el de exemplis, asumiendo un uso más restringido y convencional de esta última voz (es decir, aceptando tácitamente su mayor adecuación a la sustancia narrativa de los cuentos de la serie).

\footnotetext{
${ }^{9}$ Para la trayectoria de la literatura proverbial del autor y su relación con la evolución del Arte, véanse Francesc Tous Prieto, La forma proverbi en l'obra de Ramon Llull: Una aproximació, Master Thesis (dir. de L. Badia), Barcelona, Universitat de Barcelona-Universitat Autònoma de Barcelona, 2010, y «Breus proposicions que contenen molta sentència: els proverbis lul·lians i les "formes sentencioses"», en Studia Lulliana, 51 (2011), pp. 77-98. Para la localización de los proverbios en el Arbre exemplifical, A. Hauf, art. cit., p. 308.

${ }^{10}$ XV, pról., p. 799.
} 
Claro que tampoco faltaban precedentes de la confluencia genérica y terminológica entre unas y otras formas. En el ámbito árabe y hebreo las voces mathal y māshal definen indistintamente todo tipo de secuencias mínimas de carácter didáctico: símiles, cuentos, proverbios o dichos célebres. También en Occidente, el término exemplum y sus equivalentes vulgares podían designar ocasionalmente una sentencia o un proverbio, como sucede en diversos escritos sapienciales (muchos de ellos de origen oriental), en algunas copias del siglo XIII de la Disciplina clericalis y en la propia obra de Don Juan Manuel. De modo más concreto, Francesc Eiximenis denominaba «ejemplos breves» (exemplis breus) a las sentencias de tipo proverbial, para distinguirlas de los ejemplos propiamente dichos. Y el propio Llull, en definitiva, aludiría en el Blaquerna con el rótulo de «ejemplos abreviados» (exemplis abreujats) a ciertas formas proverbiales empleadas por los sufies. Seguramente, esos usos terminológicos (y la conocida laxitud luliana en el empleo de algunos tecnicismos) bastan por sí solos para justificar una asimilación del proverbio al ejemplo, dos formas imbricadas muy a menudo en la literatura coetánea, y encaminadas, en los escritos del Beato, a una idéntica ilustración del Arte ${ }^{11}$.

En todo caso, es posible que el diseño del Arbre exemplifical muestre algunas razones suplementarias para admitir esa convergencia entre ambos géneros. En primer lugar, conviene no olvidar que algunas series de proverbios figuran en la obra en el interior de diversos recontaments, enunciadas por cualquiera de los protagonistas de estos últimos. Basta con observar la sección correspondiente a los «ramos» del opúsculo. Allí figuran catorce relatos, presentados invariablemente como «ejemplos», con la excepción del segundo, el tercero y el séptimo, denominados «proverbios». Estos tres últimos relatos presentan, sin embargo, una estructura similar al resto, hallándose dotados también de una acción narrativa, que bien podría legitimar su consideración como recontaments. Su única singularidad reside, en efecto, en la presencia en su interior de otras tantas series de proverbios, puestos en boca

\footnotetext{
${ }^{11}$ A esa laxitud alude Rubén Luzón Díaz («Una aproximación a la noción de exemplum en la obra luliana, seguida de un breve comentario en los exempla del capítulo 62 del Llibre de meravelles», en Revista de lenguas y literaturas catalana, gallega y vasca, 12 (2006), pp. 253-276, esp. pp. 259-260), quien recoge las puntualizaciones de Jordi Rubió i Balaguer («Alguns aspects de l'obra literària de Ramon Llull» [1959], en Ramon Llull i el lul-lisme, Publicacions de l'Abadia de Montserrat, Barcelona, 1985, pp. 248-299, esp. p. 290), Josep-Antoni Ysern («Exempla i estructures exemplars en el primer llibre del Fèlix», en Studia Lulliana, 39 (1999), pp. 25-54, esp. p. 48) y Albert G. Hauf (art. cit., p. 307). Las referencias de Don Juan Manuel, Eiximenis y el Blaquerna, en A. G. Hauf, ibídem, pp. 307 y 310. Para la Disciplina clericalis y otros textos, Jacques Le Goff, Claude Brémond y Jean-Claude Schmitt, L'exemplum, Lovaina, Typologie des sources du Moyen Age Occidental, fasc. 40, 1982, p. 55. A propósito de la literatura sapiencial, véase, por ejemplo, El Libro de los Doze Sabios, ed. de John K. Walsh, Madrid, Anejos del BRAE, XXIX, 1975, cap. XXX, p. 102.
} 
de sus personajes o, en el último caso, escritos a la puerta del palacio, dada su condición de normas que debían regir la actuación del monarca. Todos esos proverbios, por lo demás, proceden de otra obra luliana (el tratado De centum nominibus Dei) y en ese contexto original habían sido presentados como «versos» para ser cantados, al modo en que los «sarracenos cantan el Corán en sus mezquitas» (es decir, a la manera de los ayat de las suras coránicas ${ }^{12}$ ). Seguramente, es ese origen tan ajeno al género ejemplar el que explica el interés luliano por dotar a esos proverbios de un marco narrativo: un modo de presentación que sin duda favorecería su inserción en un contexto tan específico como el del Arbre exemplifical.

La integración del proverbio en el opúsculo (es decir, su consideración como una «forma ejemplar») podía llegar también por una segunda vía, relacionada con la posibilidad de su lectura como un recontament abreviado o en germen. Los textos retóricos habían establecido esa «reversibilidad» entre los ejemplos y las formas sentenciosas, entendidos como dos modos alternativos para la enunciación de una lección, muchas veces, única. En la tradición antigua y humanística, además, el proverbio podía tener su origen en una anécdota ejemplar o, al menos, en una situación enunciativa concreta y puntual, y solía ser presentado acompañado de una glosa que declarara su procedencia y su sentido exacto, a menudo de carácter críptico ${ }^{13}$. Por supuesto, la relación de esos proverbios clásicos con los que integran el Arbre exemplifical es meramente tangencial. Pero la primera de las secuencias del tratado luliano muestra un evidente paralelismo con aquellos presupuestos. El inicio del pasaje propone una suerte de enigma: «El fuego quiere que su calor sea bueno en el agua para que su bondad tenga gran virtud; y por eso dijo el agua al aire que la recordase en su enfermedad». De modo inmediato, un monje solicita a un conocido personaje luliano, Fèlix, que exponga «aquel proverbio», y este último declarará su sentido a través, precisamente, de un recontament. En él, el aire yace enfermo de dos dolencias, a causa del amor al fuego y de la sequedad causada por ese mismo fuego. El agua propone al aire que se acerque a ella, pero el aire prefiere sufrir su dolor antes que traicionar a su semejante y amado. Esa glosa de Ramon en forma de cuento ilumina la esencia genérica del proverbio: éste se concibe, en efecto, como

${ }^{12}$ A. G. Hauf, art. cit., pp. 308-309. Y cfr. Arbre de ciència, XV, IV, pp. 817-826.

${ }^{13}$ María Pilar Cuartero Sancho, «Las colecciones de adagia en la literatura latina del Renacimiento», en Actas del III Congreso Internacional de Humanismo y Pervivencia del mundo clásico. Homenaje al profesor Antonio Fontán (Alcañiz, 8-13 de mayo del 2000), coord. de J. M. Maestre Maestre et alii, vol. III, Madrid, Ediciones del Laberinto, 2002, pp. 1585-1590, esp. p. 1585. 
una proposición mínima, capaz de resumir y, de algún modo, de sustituir a un relato o recontament ${ }^{14}$.

A la luz de esa secuencia inicial, por lo demás, podría suponerse que el Beato concibe el exempli como una unidad formada por la suma de un recontament y un proverbi. La propia ambigüedad del prólogo (donde se hablaba, como sabemos, de la división del ejemplo en «dos partes») reforzaría esa posibilidad. Pero no parece necesario llegar tan lejos: para el Beato, probablemente, relatos y proverbios constituyen dos modalidades ejemplares alternativas, aunque potencialmente filiadas ${ }^{15}$. En este último sentido, la «dualidad» del primero de los ejemplos del Arbre exemplifical sería excepcional. Quizá incluso voluntariamente excepcional. Es posible, en efecto, que Llull haya querido mostrar en ese inicio de la obra tanto la naturaleza diversa de las dos categorías ejemplares cuanto la estrecha vinculación que ambas podían llegar a ostentar. En el resto del tratado, en efecto, las dos categorías se mostrarán generalmente de modo exento, aunque no falten algunos ecos de esa latente filiación «genética». Muchos de los proverbios lulianos cobran, por ejemplo, la forma de un diálogo entre varios personajes, trasladando una incipiente ilusión dramática:

Lloró el agua porque el fuego la calentaba en verano, y quejóse de ello al sol; y la luna reprendió al agua porque se quejaba a su enemigo [...] Dijo el agua al fuego que con ella se lavan las señoras la cara para estar bellas y blancas; el fuego dijo al agua que por él desean las mujeres a sus maridos [...] Pidió el mulo a su madre, la yegua, que no dijese que él era hijo del asno, y ella dijo al mulo que él lo significaba en su figura, por lo que ella ocultarlo no podía ${ }^{16}$.

Tan sólo la brevedad de esas secuencias podría legitimar su calificación como proverbis, toda vez que su contenido resulta similar al de cualquier recontament del texto. La adecuación de ambas formas a la exposición del Arte ha acabado por minimizar sus fronteras. Algunos de los recontaments del Arbre exemplifical han pasado a ser una insulsa traslación de la relación teórica entre los entes artísticos, renunciando a algunas de las cualidades tradicionales del género (la intriga narrativa o el peso del final del relato). Y muchos de los proverbis han atenuado o abandonado ese cariz metafórico o sentencioso que le era propio en la tradición para acabar pareciendo simples resúmenes de

\footnotetext{
${ }^{14} \mathrm{XV}$, I, p. 799. Y véase el análisis de R. Pring-Mill, art. cit.

${ }^{15}$ Ll. Cabré, M. Ortín y J. Pujol, art. cit., pp. 140-141, quienes rebaten la opinión de R. Pring-Mill (art. cit.) y J. Rubió i Balaguer (art. cit., p. 289).

${ }^{16}$ XV, II.1, VI.3, pp. 804-805 y 832. Al respecto de esa dimensión narrativa, Ll. Cabré, M. Ortin y J. Pujol, art. cit., pp. 140-142, A. G. Hauf, art. cit., pp. 322-331, y F. Tous Prieto, op. cit., p. 81.
} 
aquellos mismos principios artísticos: «Simple movimiento circular no pasa por medio alguno [...] Ningún ángel es ligero ni pesado ${ }^{17} \gg$. Es esa proximidad temática y formal entre narraciones y proverbios la que favorece, así pues, su compilación conjunta en la obra, y su concepción como dos variedades posibles del exempli. Al final del Arbre exemplifical, el lector ha podido comprobar aquello que Ramon Llull había mostrado en la primera de sus secuencias: muchos de los proverbios pueden ser leídos como recontaments en germen, como, también a la inversa, muchos de estos relatos podrían ser fácilmente convertidos en proverbis. De modo tácito, el texto ofrece una invitación para recorrer ese camino que lleva de una forma a otra, como un aspecto más de la ejercitación de las estrategias ejemplares propuesta al lector desde el prólogo. También a este propósito, la sensación que sugiere el Arbre exemplifical es la de un texto inacabado, la de un repertorio in fieri.

\section{Cuentos verosímiles y relatos marianos}

Por lo que respecta de modo exclusivo a los recontaments, el texto concede todavía un notable espacio a algunas formas ensayadas por el autor en su producción anterior. No faltan allí, de hecho, los cuentos verosímiles, protagonizados por personajes humanos y sustentados en aquella misma galería de situaciones que asomaban por el Blaquerna o el Llibre de meravelles. Como sucedía en esas novelas, los cuentos del Arbre exemplifical son fruto de la imaginación del autor, aunque recreen en ocasiones motivos tradicionales. Un caso significativo a este respecto es el representado por el cuento de «El astrólogo malvado». La trama del mismo es notablemente original pero, como demostró Lola Badia, asume dos temas de larga tradición literaria: el del adivino que no es capaz de prever su propia muerte (asunto tan antiguo como la Eneida) y el de la doncella alimentada con veneno (motivo presente en la famosa «Carta de Aristóteles a Alejandro Magno», difundida en Occidente a partir del siglo XII en el Placides et Timéo ${ }^{18}$ ).

${ }^{17}$ XV, II.9-10, p. 808. También en la Rhetorica nova, algún ejemplo constituye la amplificación de un proverbium (aunque las formas acogidas bajo este término por Llull sean ante todo sentencias, y no proverbios propiamente). Así, la lección que subyace al conocido ejemplo de «Los monos, la luciérnaga y el ave» (sobre el que volveremos después) es paralela a una de las sentencias incluidas en la sección «De pulcris proverbiis». Cfr. Rhetorica nova, ed. de Mark D. Johnston, Ramon Llull's New Rhetoric. Text and Translation of Llull's "Rhetorica Nova», Davis, Hermagoras Press, 1994, 2.4.13 y 2.7.13, pp. 21 y 28.

${ }^{18}$ El cuento, en XV, III.10, p. 814. Y véase L. Badia, «La literatura alternativa de Ramon Llull», art. cit., pp. 17-21. 
Ese equilibrio entre tradición y novedad sustenta también la composición de un milagro de Nuestra Señora presente en la obra. El milagro aparece engastado en un relato mariano más amplio, referido por Ramon a un monje, y concebido como «ejemplo de la rama maternal». En este relato, las dignidades divinas ruegan al Hijo de Dios la creación de un hombre entre las criaturas y Éste ordena para ello la previa concepción y natividad de Nuestra Señora. El hecho colma al Mundo de júbilo, haciéndole perder cualquier «miedo de desesperanza». Al hilo de esa alusión al concepto de la esperanza, Ramon introducirá el milagro citado, acaecido en Inglaterra. En él, un joven pretende peregrinar a un famoso altar de la Virgen, pero su madre se opone, temerosa de que los familiares de un caballero muerto por su marido tomen venganza en aquel hijo. El joven reprende a su madre por su falta de esperanza e inicia su viaje, siendo encomendado por ella misma a Nuestra Señora. A una jornada de su destino, los enemigos lo prenden, cortándole las manos y sacándole los ojos. El joven logra llegar hasta el templo y, ante la Virgen, supone que su madre «había fallado en su esperanza». Pero su sospecha es infundada: al oír la noticia del horrible ataque, la madre se niega a creerla, confiada en la protección de María. Finalmente, se encamina hacia la iglesia, donde encuentra a su hijo sin mal alguno, como ella ya había adivinado ${ }^{19}$.

El relato recuerda enormemente la trama de una de las Cantigas de Santa Maria de Alfonso X el Sabio. En ella se narra un milagro recogido de fuentes orales, acaecido esta vez en Francia y protagonizado también por una madre y un hijo. Aquí, el joven decide acudir en romería al santuario de Santa María de «Albeza», haciendo caso omiso al temor de su madre a sus enemigos. En el camino, éstos lo apresan y uno de ellos le arranca los ojos y le corta las manos. Con todo, consigue ser llevado por unos peregrinos hasta la iglesia, confiado en ser curado allí por Santa María. En esta ocasión, la noticia provoca que la madre quede consternada («más negra que la pez o el carbón»), aunque se dirige a Albeza y ruega a Dios por la sanación del hijo. Finalmente, la Virgen restituye a este sus manos y le hace crecer unos ojuelos hermosos y pequeños, «como de perdiz» ${ }^{20}$. La filiación entre el milagro luliano y la cantiga (o, más probablemente, su deuda compartida con una fuente remota) está fuera de duda. Pero no son menos evidentes las divergencias entre ambos relatos. Al margen de ese enigmático desplazamiento de la ubicación geográfica del caso, Ramon Llull ha operado en el mismo algunas sutiles transformaciones, encaminadas a reforzar el conflicto entre la esperanza y

\footnotetext{
${ }^{19} \mathrm{XV}$, III.13, pp. 815-816.

${ }^{20}$ Alfonso X, Rey de Castilla, Cantigas de Santa Maria, ed. de Walter Mettmann, Madrid, Castalia, 1986-1989, Cant. 146 , vol. II, pp. 127-130.
} 
la desesperanza que justificaba su inserción en el texto. A esa luz han de entenderse los reproches del joven, antes del viaje y ya en la iglesia, hacia la aparente falta de fe de su madre. $\mathrm{O}$, en el lado contrario, la infinita confianza de esta última en la Virgen, al negarse a asumir como ciertos los daños sufridos por el hijo. Con esas modificaciones, Llull estaba traicionando toda la voluntad de historicidad que la narración manifestaba en la tradición oral y escrita. De modo consciente (y quizá inequívoco para aquellos lectores que conocieran esa misma tradición), el autor había derivado la trama del relato hacia el ámbito de la ficción, como sucedía con tantos otros pasajes del Llibre d'Ave Maria o del Llibre de santa Maria.

Hemos comentado en otro lugar las implicaciones de esa transgresión de las convenciones del género del milagro mariano ${ }^{21}$. Pero esa transgresión ha de entenderse, en este caso concreto, en el contexto de otras recreaciones literarias de la figura de la Virgen presentes en el Arbre exemplifical. Por ejemplo, aquellas que convierten a María en personaje o en narradora de un cuento. Alguno de esos relatos revela, en efecto, una libertad imaginativa sin límites. En uno de ellos, un monje permanece por la noche en la iglesia para orar a Nuestra Señora. María se le aparece sentada sobre el altar y llorando, contrariada por la actitud de todos aquellos que creen que no habría sido Madre de Dios de no existir el pecado (cuando había adquirido esa condición sólo porque Dios había deseado hacerse hombre). María explica al monje la cuestión refiriéndole una larga conversación entre la Voluntad y el Entendimiento, en la que éste defiende su derecho a escudriñar los misterios divinos, frente a los reparos de aquélla, partidaria de los méritos exclusivos de la fe. Ese diálogo constituye así una suerte de cuento mínimo, presentado por María con la misma fórmula («Cuéntase que...») que introducía el propio relato del monje y la Virgen que le servía de marco. El personaje de Nuestra Señora se erigía así en el nexo entre ambos cuentos, relacionados de acuerdo con un procedimiento (el de las «cajas chinas») de claras resonancias literarias ${ }^{22}$.

Esa proyección literaria de la figura de Nuestra Señora cobra un perfil todavía más sugerente en otro relato. En él, el Paraíso se ríe del Infierno «porque era negro», y éste se burla de aquél porque está casi vacío, a causa de los pecados de los hombres. Dolido por el escarnio, el Paraíso ruega a la Virgen que solicite a su Hijo que ningún hombre sea en adelante condenado. La petición adopta así el tono de los ruegos presentes en numerosos milagros

${ }^{21}$ José Aragüés, «Ramon Llull: la invención del milagro mariano», en Estudios de Filología e Historia en honor del profesor Vitalino Valcárcel, ed. de I. Ruiz Arzalluz et alii, Vitoria-Gasteiz, Universidad del País Vasco-Euskal Herriko Unibertsitatea, 2014, pp. 91-109.

${ }^{22} \mathrm{XV}$, VII.12, p. 840. 
marianos. Pero, en este caso, la respuesta de Nuestra Señora consistirá exclusivamente en la narración de un cuento. En él, una reina pasea por un vergel con su hijo en brazos cuando se ve sorprendida por un lobo, que rapta al niño para entregarlo como alimento a la loba y a sus crías. La loba, sin embargo, decide criar al niño, quien pasa a ser compañero de juego de los lobeznos. Al crecer, el niño adopta las costumbres de su nueva familia, matando a los hombres y robando sus ovejas. El cuento está tejido, por supuesto, sobre un viejo motivo folclórico. Pero, en este caso concreto, sirve únicamente a María para justificar la inoportunidad de ese milagro solicitado por el Paraíso, erigiéndose en una explicación metafórica del origen del mal en el mundo: un mal imputable a aquellos hombres «que no se parecen a sus padres y madres de buenas costumbres», al propio lobo (evidentemente, el diablo) y a los infantes que debieran haber velado por la seguridad de la reina y de su hijo (los malos eclesiásticos ${ }^{23}$ ). Como sucedía en el cuento anterior, la Virgen asume la voz del autor, ilustrando por medio de la ficción algunos de los principios esenciales del pensamiento luliano. María desborda así su condición de personaje en ese universo literario ideado por el Beato, para convertirse en uno de los «creadores» del mismo ${ }^{24}$.

\section{Los ecos de la fábula}

También las fábulas animalísticas asoman por el Arbre exemplifical. Lo hacen de un modo discreto, pero no exento de interés. Algunas de ellas figuran en el último capítulo, correspondiente a los «frutos». Allí, un asno convence a un cerdo de que los cuidados que recibe sólo tienen por finalidad su engorde, provocando que éste huya al bosque. Algo más abajo, el Mérito narra a la Virtud otro cuento, en el que un caballo convence a su dueño, un rey, de que el halcón sólo le sirve por la comida, y no por amor ${ }^{25}$. Con todo, la mayor parte de los apólogos animalísticos se acumulan en el capítulo dedicado a las «ramas» del Arbre exemplifical. El extenso exempli de la «rama sensual» incluye, por ejemplo, dos secuencias de ese tipo: la deliciosa conversación

\footnotetext{
${ }^{23}$ XV, V.11, p. 830.

${ }^{24} \mathrm{La}$ libertad en el tratamiento de la figura de María se extiende a muchos otros personajes. María, Cristo y San Pedro protagonizan el siguiente cuento en la obra (XV, V.12, p. 420). Y en uno anterior figuran San Miguel, San Gabriel, Lucifer y el propio Dios (XV, IV. 11, pp. 80-81). Por lo demás, María reaparece como personaje en el Liber natalis pueri parvuli Christi Jesu (1311), donde ordena a las seis damas alegóricas que protagonizan la obra (Alabanza, Oración, Caridad, Contrición, Confesión y Satisfacción) que exhorten al rey de Francia a aceptar la misión de tomar Tierra Santa (ed. de Hermogenes Harada, Turnhout, Brepols, ROL, VII, 1975, pp. 19-73, esp. p. 71).

${ }^{25}$ XV, VII.3 y 6, pp. 836-837.
} 
entre una rata y su hija, que quería ser amiga de un gatito, y la historia del caballo y el león que decidieron ir en romería. Ambos relatos (junto a un tercer ejemplo, de carácter verosímil) aparecen subordinados de acuerdo con el citado procedimiento de las «cajas chinas», como veremos algo más abajo. La siguiente secuencia (correspondiente a la «rama imaginal») incluye también una fábula, en la que una oveja ve morir a sus dos corderos a manos de un lobo y de un hombre, respectivamente, ante la presencia de un cuervo, que explicará a una paloma por qué la madre adopta una actitud diferente ante ambas muertes. Algo más familiar había de resultar a los lectores la secuencia inmediatamente posterior (el exempli de la «rama corporal humanal»), que, por su trama y por sus personajes, evoca de manera transparente el universo del Llibre de les bèsties. La narración se inicia con la consulta de un rey a su pueblo acerca del estado del reino, que da lugar a las quejas del ciervo por la muerte de los animales a causa de las flechas de los hombres. La zorra aconseja al rey que envíe mensajeros al hombre para tratar la paz, pero el perro recela de ella y advierte al rey de sus malas intenciones. El rey elige al perro para la tarea, ante la protesta del lobo, quien recuerda la tradicional amistad entre los perros y los humanos. Finalmente, la embajada es entregada al lobo, quien se dispone a aprovechar su viaje para devorar los ganados. Pero, al llegar a su destino, muere de un flechazo, perdiéndose la misión ${ }^{26}$.

La deuda con los escritos anteriores del autor es así mismo evidente en la secuencia que cierra el extenso exempli de la «rama imperial». Esa secuencia (narrada por un sayón al rey) constituye una versión más de la fábula oriental de «Los monos, la luciérnaga y el ave», adoptada previamente por Llull en el Blaquerna y en el Llibre de les bèsties, y más tarde incorporada a la Rhetorica nova. Las variantes de esas cuatro versiones, analizadas en su momento por Llinarès y Hauf, constituyen un buen resumen de la libertad que preside el tratamiento de la materia tradicional en la obra luliana ${ }^{27}$. Pero en modo alguno permiten intuir la transgresión que, a ese mismo propósito, mostrarán algunos otros ejemplos del Arbre exemplifical.

\section{Los relatos «artísticos»}

Buena parte de las secuencias del Arbre exemplifical, en efecto, escapan a los moldes fijados por la tradición del ejemplo verosímil o de la fábula, para

${ }^{26} \mathrm{XV}$, III.3, 4 y 5 , pp. 810-811.

${ }^{27} \mathrm{XV}$, III.8, pp. 812-813. Véanse Armand Llinarès, «Les singes, le ver luisant et l'oiseau. Note sur l'utilisation répétée d'une même fable dans l'oeuvre de Lulle», en Romania, 108:1 (1987), pp. 97-106, y A. G. Hauf, art. cit., pp. 314-319. Y cfr. J. Aragüés, «Llull and Medieval Exemplary Literature», cit. 
imponer un universo de ficción propio. Esas secuencias, que hemos dado en agrupar bajo el nombre de «ejemplos artísticos», están habitadas por personajes correspondientes a todos los niveles de la realidad. Por allí asoman diversas nociones espirituales (los vicios y virtudes, las potencias del alma), los conceptos centrales de la cosmología y la teología del autor (las dignidades divinas, los principios relativos, los cuatro elementos), numerosas abstracciones de carácter universal (los tiempos verbales, las formas geométricas), algunos objetos simbólicos (la espada, el escudo o la corona) y una suma casi infinita de entes correspondientes al mundo celestial (el sol, los planetas) y a las distintas esferas del mundo elementado (el oro, la rosa, la pimienta o, según sabemos, un herpes). Todos esos seres, materiales o espirituales, aparecen debidamente personificados (es decir, dotados de la palabra y de otros atributos humanos), de acuerdo con un procedimiento similar al que informa la creación de los protagonistas de la fábula animalística o del relato alegórico. En este sentido, es verdad que existe un cierto hilo de continuidad entre esas formas tradicionales y el «ejemplo artístico». Pero, en el caso de los extraños personajes que pueblan este último, es justamente la ausencia de una tradición la que otorga a las narraciones el aspecto de meros artificios o constructos verbales, marcando su distancia con respecto a las modalidades más convencionales de la literatura ejemplar. Una distancia, claro está, acentuada por la propia singularidad de las tramas de esos relatos, encaminadas a trasladar a un universo de ficción aquellas complejas relaciones de afinidad y contrariedad entre los entes propuestas en las páginas teóricas del Arte.

El diseño de alguno de esos ejemplos revela, con todo, un cierto aprovechamiento de algunos argumentos tradicionales. Así sucede en el caso del «ejemplo de la cantidad celestial», situado entre las «hojas» del opúsculo, y estudiado con precisión por Badia. Su fuente remota es el «Juicio de Paris», difundido en la Edad Media a través de obras como la Crónica Troyana de Guido della Colonna o el Speculum Historiale de Vincent de Beauvais. Como es bien sabido, la leyenda original narra la disputa en torno a la primacía en la hermosura de las diosas Atenea, Hera y Afrodita. Una disputa que tenía como premio la manzana de oro entregada por Éride (diosa de la discordia) y que hubo de resolver el mortal Paris en favor de Afrodita, tras escuchar los argumentos (y los ofrecimientos) de las tres diosas. Muy poco de todo ello permanece en el ejemplo luliano. El Beato recuerda, eso sí, la idea de la controversia entre tres personajes y el motivo de la manzana de oro como premio, pero la naturaleza de esos personajes delata ya desde el comienzo toda la distancia del ejemplo con su fuente clásica: «Cuéntase que el Círculo, el Cuadrángulo 
y el Triángulo se encontraron en la Cantidad, que era su madre, la cual tenía una manzana de oro, y preguntó a sus hijos si sabían a quién debía darla...». En el cuento luliano, los méritos de los protagonistas nada tienen que ver ya con la belleza, y sí con las relaciones que esas formas geométricas mantienen entre sí y con distintos entes de la Creación. De ese modo, el Círculo aduce su primogenitura y mayor velocidad, el Cuadrángulo defiende hallarse más cercano al hombre que el Círculo y ser más grande que el Triángulo, y este último declara estar más próximo al hombre que el Círculo y ser más semejante a Dios que el Cuadrángulo. El pleito se resuelve en favor del Triángulo, generando una nueva disputa en la que participan esos y algunos otros personajes (don Aries, don Saturno y sus respectivos hermanos). Todos ellos censuran la decisión de la Cantidad, incluido el beneficiario del premio, molesto por recibir «una manzana redonda, que no era de su figura ${ }^{28}$ ».

La presencia de esas curiosas personificaciones otorgaba al cuento un aire extraño, ante todo para aquellos lectores que conocieran su punto de partida. Pero esa sensación de extrañeza afecta por igual a otros ejemplos sin sustento tradicional, en los que esas extravagantes personificaciones protagonizan tramas propias del relato verosímil, mezclándose incluso con los personajes tradicionales de este último. Una excelente muestra de todo ello la ofrece una de las secuencias de la primera sección del texto. Allí, un padre (la Pimienta) contrae matrimonio con sus dos hijas (Mayoridad y Minoridad), engendrando en ellas dos nuevos hijos, que matarán a ese padre. El cuento es escuchado por Don Monje, quien pide a Ramon una exégesis del mismo. Para ello, Ramon introducirá un nuevo relato. El inicio del mismo («Cuéntase que a un sastre...») parece situarnos ante un cuento protagonizado por personajes convencionales, pero por allí asoman de inmediato dos objetos (la Aguja y las Tijeras), que engendran dos hijas de carácter alegórico (Riqueza y Honra), con las que el sastre se casará, para tener un nuevo hijo, llamado Privación del Fin de Honra y de Riqueza ${ }^{29}$.

\section{Artificios narrativos}

La convivencia en un relato de seres humanos y de entes artísticos no es excepcional. Lo habitual, sin embargo, es que ambos tipos de personajes no aparezcan en una misma secuencia o que, de hacerlo, figuren en dos niveles

${ }^{28}$ XV, V.9, p. 829. El análisis, en L. Badia, «La literatura alternativa de Ramon Llull», art. cit., pp. $22-25$

${ }^{29}$ Dos excelentes análisis de la estricta correspondencia entre el relato y la teoría artística ofrecen L1. Cabré, M. Ortin y J. Pujol, art. cit., pp. 144-145, y L. Badia y A. Bonner, op.cit., pp. 152-155. 
narrativos distintos. En este sentido, los protagonistas de un cuento verosímil pueden introducir un relato acerca de los encuentros y desencuentros entre diversas realidades abstractas o alegóricas. Pero también existen casos más curiosos, en los que son esos entes lulianos (los vicios y las virtudes, los cuatro elementos) los que dialogan y refieren ejemplos protagonizados por seres humanos, ofreciendo así una auténtica inversión de la realidad. Por supuesto, no faltan precedentes de esa ruptura de la lógica narrativa, ni en la obra luliana ni en una tradición fabulística que no dudaba en hacer de los animales narradores de cuentos perfectamente verosímiles. Pero, de nuevo, es la ausencia de una tradición para los ejemplos artísticos del Beato la que acaba por ubicar el Arbre exemplifical en una atmósfera ciertamente sorprendente. La décima secuencia de las «raíces» del opúsculo incluye, por ejemplo, un cuento protagonizado por dos caballeros, quienes pleitean sobre la posesión de un castillo. Ambos sobornan al juez, uno con mil florines y el otro sólo con cien. Enterado de todo el rey, pregunta a su consejo la causa de esa diferencia. Un sabio deduce que el caballero de los cien florines era el dueño legítimo del castillo y por eso no había querido gastar una suma excesiva en aquello que le pertenecía por derecho. El cuento (verdadero ejemplo de juicio salomónico) forma parte de esa hermosa galería de relatos verosímiles prodigados por el autor en tantas de sus obras. Pero, en este caso, está narrado por un personaje alegórico (la Sequedad), para excusar su intervención como juez en un pleito entre la Rosa y la Pimienta, enfrentadas por su defensa respectiva de las bondades del Agua y del Fuego.

También la siguiente secuencia muestra un elocuente caso de inversión de la realidad. En ella, el Fuego quiere engañar al Agua, pidiéndole que le ayude a fabricar la Pimienta, a cambio de colaborar con ella en la creación de la Calabaza. El Agua responde con un ejemplo, que revela metafóricamente el engaño que subyace en esa interesada propuesta. El cuento, de nuevo de naturaleza verosímil, narra el triste final de un matrimonio de conveniencia entre el hijo de un caballero pobre deseoso de riqueza (constituido en figura del Fuego), y la hija de un labrador rico tentada por la obtención de honra (trasunto del personaje del Agua). Aquí, son las relaciones entre los seres humanos las que ilustran metafóricamente las tensiones entre los entes naturales, y no a la inversa, como era el caso en el grueso de la tradición ejemplar ${ }^{30}$. El Arbre exemplifical da cobijo a los ejemplos más osados y a los más convencionales, combinándolos de modo diverso gracias a la consabida multiplicación de los niveles narrativos. El texto concede así un espacio notable

${ }^{30} \mathrm{XV}, 1$, p. 802 . 
a esa ejercitación de las estrategias de la ejemplaridad ya ensayadas en el Llibre de meravelles, llenándose de juegos y ecos especulares. Especialmente interesantes, a ese respecto, resultan algunas secuencias, como aquella que conforma el «ejemplo de la rama sensual», a la que aludíamos unas líneas más arriba. El relato se inicia con una trama propia de la fábula animalística. En ella, una ratita declara a su madre que desea trabar amistad con un gatito que juega con una pluma, considerando que este último no podía conocer todavía la tradicional «contrariedad» existente entre unas y otras especies. Gracias a esa amistad, pensaba la ratita, el gato no le haría daño cuando creciera. La madre responderá a su hija con un cuento verosímil. En él, un burgués mata a un caballero y, para restaurar la paz entre los amigos de uno y de otro, decide casar a su hija con el hijo del difunto. En ese punto, la mujer del burgués introduce una nueva fábula, protagonizada por un caballo y un león. Ambos desean ir en romería, pero a última hora el caballo decide no emprender el viaje, ante el riesgo de ser devorado por el león si éste no encontraba otra comida. La fábula hace reflexionar al burgués, que decide no casar a la hija, recordando que los caballeros son orgullosos «y no perdonan felonías ${ }^{31} \gg$. El extenso relato concluye aquí, sin declarar de modo explícito la resolución del cuento que lo encabezaba (el de la ratita y su madre). Por supuesto, esa declaración resultaba absolutamente innecesaria, pues el final de esa fábula aparece tácitamente reflejado (y anticipado) en los dos cuentos subordinados a su trama. Los tres niveles de la narración recrean, de algún modo, el mismo cuento.

Esa multiplicación de un único argumento, potencialmente infinita, nos envuelve de nuevo en una atmósfera de absoluta irrealidad, delatando un afán de experimentación literaria no muy lejano, como decíamos, al que inspiraba buena parte de los relatos del Llibre de meravelles. Nutrido de un modelo ejemplar sustancialmente nuevo (el del «ejemplo artístico», tan ajeno a la concepción medieval del género como a los tanteos previos de la escritura del autor) y desnudo ya de todo marco narrativo, el Arbre exemplifical seguía así haciendo suya la única condición perenne, al parecer, de la literatura ejemplar luliana: su ausencia de límites, el sacrificio de todas sus fronteras en aras de una difusión del Arte sentida como su único fin posible.

Recibido: 01/04/2015

Aceptado: 17/06/2015

${ }^{31}$ XV, III.3, p. 810. 
RESUMEN: El Arbre exemplifical ofrece numerosas claves a propósito de la evolución del exemplum luliano. En el texto confluyen algunas formas ya ensayadas por el autor (ejemplos verosímiles, fábulas) con otras narraciones de aspecto mucho más original, protagonizadas por personificaciones de todos los entes, materiales o espirituales, del Arte («ejemplos artísticos»). Esos cuentos se presentan allí de manera desnuda, sin sujeción a un marco novelístico o discursivo, al modo de un ordenadísimo instrumentum al servicio del lector. El Arbre exemplifical desborda así su intención inicial (la iluminación del Arbre de ciència), para erigirse en un repertorio de formas preparadas para su inserción en cualquier discurso. Esas formas, además, se ofrecen como modelos para la creación de nuevas secuencias, confirmando el carácter experimental e inacabado que ostenta tantas veces la literatura ejemplar del Beato.

Palabras clave: Ramon Llull. Arbre exemplifical. Arbre de ciència. Exemplum. Fábula. Proverbio. Experimentación narrativa.

\section{Tradition and InNOVation OF the LuLLIAN EXEMPLUM: the ARBRE EXEMPLIFICAL}

ABstract: The Arbre exemplifical occupies a very important space in the evolution of Llull's exemplum. The text joins various forms which are already utilized by Llull (realistic examples, fables) with other stories of much more originality, featuring personifications of all entities, material or spiritual, from the Art («artistic examples»). Those stories are stripped of their attachment to a fictional or discursive framework, and function as an orderly instrumentum to serve the readers. The Arbre exemplifical exceeds its initial intention (to illuminate the Arbre de Ciència), by establishing itself as a repertoire of narrations prepared for insertion into any speech. These narrations are also offered as models for the creation of new stories, confirming the experimental and unfinished character that frequently embodies Llull's exemplary literature.

Keywords: Ramon Llull. Arbre exemplifical. Arbre de ciència. Exemplum. Fable. Proverb. Narrative experimentation. 